\title{
Study on the Evaluation of Social Stability Risk of Agricultural Transferring Populations Citizenization Based on Fuzzy Analytic Hierarchy Process
}

\author{
Xibo Sun ${ }^{\mathrm{a}}$, Xiaodong Shi ${ }^{\mathrm{b}}$ and Peng Wang ${ }^{\mathrm{c}}$ \\ School of Economics and Management, Harbin Engineering University, Harbin, 150001, China \\ asunxibo2001@163.com, bdonger2014@126.com, c125388670@qq.com
}

Keywords: Agricultural transferring populations, Citizenization, Social stability risk assessment, Fuzzy AHP method, and Roots theory.

\begin{abstract}
A large amount of agricultural populations are transferring to the city in the new citizenization process. Considering the large scale of such a group, the extensive regional as well as industrial distribution, and profound impact on the overall social stability, it is of great significance to accurately evaluate the social stability risk of the citizenization of agricultural populations. This essay applies the grounded theory to identify the corresponding social stability risk factors and studies the risk assessment of the social stability within the agricultural transferring populations based on the fuzzy analytic hierarchy process (Fuzzy AHP). This paper constructs the risk evaluation index system by five kinds of first-level indicators and 14 second-level indicators, including political risk, social risk, institutional risk, security risk and perceived risk. The Fuzzy AHP comprehensive evaluation method is used to establish the social stability risk assessment model of the agricultural populations. We take the agricultural transferring populations in Heilongjiang Province as an example in this article and the empirical analysis shows that the risk of social stability is at a moderate risk level. This approach can avoid the one - sidedness of risk factor identification and the subjectivity of AHP.
\end{abstract}

\section{Introduction}

Promoting the transfer of agriculture Population is the core of the new urbanization. The agricultural transfer population is the most important and vulnerable group in the process of urbanization and its particularity makes it easily for them to become a high risk group [1]. Within the scope of the existing urban carrying capacity, land conflict, neighborhood events, basic public service inequality and other issues will cause social stability risk intensified. We should make a scientific assessment of the social stability risk of the agricultural transfer population firstly to effectively maintain the social stability and smoothly promote the agricultural population migration. Then we can take corresponding measures to keep the social stability risk within the controllable range.

\subsection{Social Stability Risk Identification, Evaluation and Definition}

Tong Xing said, the social stability risk refers to the economic, political, environmental and other factors that would may cause changes in social conflicts and endanger social stability as well as disrupt the social order for more[2]. Yang Fangyong pointed out that the social stability risk refers specifically to the social system. The risk of public conflict may cause by a major issue's misconducted within some economic, political, cultural and other kinds of systems [3]. Guo Xiuyun, Gao Shan and other scholars further proposed that in the process of social stability risk assessment, we should focus on the combination of public participation and analysis evaluation, the sharing of social evaluation resource. Then clear the power, responsibilities and the follow-up dynamic tracking monitoring of each party [4]. In general, the matter that related to the vital interests of the masses and involving a wide range of people need to use social stability risk assessment [5]. China has entered a high-risk period of social stability, research in the law of social stability and the causes of social contradictions plays an important role in maintaining the social stability, grasping the strategic opportunity and achieving sustainable development [6]. 


\subsection{Fuzzy-AHP Method and Roots Theory}

Fuzzy AHP uses fuzzy mathematics to introduce the concept of membership degree, quantifies the fuzzy concept of evaluation index. It determines the fuzzy weight by analytic hierarchy process, then constructs fuzzy evaluation matrix and evaluates the evaluation value. After that, it applies the evaluation model and the multi-level comprehensive evaluation method, step by step, reverse the calculation to get on comprehensive weighted evaluation in a bottom-up way. At last, we can get a comprehensive measure of evaluation indicators[7]. The roots theory was founded by Anselm Strauss and Barney Glaser of Columbia University in 1976.It is a bottom-up generalized research methods, extracts new concepts and categories from the phenomenon as well as finds a new link and interactive mode[8]. Roots theory is a method of qualitative research, doing the induction analysis from the data and concerning about the concept of the framework or the formation of theory [9]. The goal of roots theory is to explain that behavioral patterns relates to the participant or the issues involved in the participant through generating theory [10]. Fuzzy comprehensive evaluation method is more systematic and suitable for solving uncertain problems or the problems which are difficult to quantify. It's more reasonable to reduce or avoid the subjective factors of the error compared with the traditional analytic hierarchy process.

This paper uses the roots theory model and Fuzzy AHP comprehensive evaluation method to evaluate the social stability risk of agricultural population migration. Firstly identify social stability risk factors by roots theory, then evaluate the social stability risk of the citizenization of agricultural population. This paper makes an empirical analysis on the risk assessment of the social stability of the agricultural population and take Heilongjiang Province as an example. It aims to achieve a more comprehensive and objective evaluation of the results. It can also eliminate the subjectivity of qualitative evaluation in the past.

\section{Text Model Building}

\subsection{The Establishment of the Roots Theoretical Model}

\subsubsection{Data Collection and Theoretical Sampling}

Heilongjiang Province has a large amount of agricultural transfer population, so it is not realistic to transfer all the agricultural population at one time. The process can be divided into some strategic steps to implement. The first step is to leave the countryside, landless peasants or seasonal agricultural transfer labor leave the countryside. The second step is to enter the city, through odd jobs, short jobs, do wholesale and retail business or find friends and relatives to take root in city. The third step is citizenization, with the increase in working hours and the depth of the urban population integration, we can realize citizenization through the children's education resettlement, local resettlement and registration changes. In summary, the agricultural transfer population is mainly through the following three procedures gradually realized:

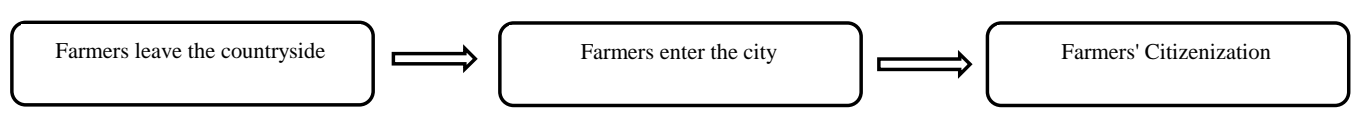

Fig. 1 The Process of citizenization of Agricultural Transfer Population

As the agricultural transfer population of the social stability of the risk factors have their particularity, we can identify the social stability risk factors of the three processes within agricultural transfer population's citizenization through the open decoding, spindle decoding and core decoding process of roots theory. The identified risk factors are more consistent with the social stability risk factors in a given environment .In the process of data collection ,we should make full use of internet, journals, interviews etc. to collect as much information as possible .In order to identify the social stability risk factors of the agricultural transfer population's citizenization comprehensively, We select 3/4 of the sample data for coding and model construction randomly and the other 1/4 is used as a theoretical saturation test. 


\subsubsection{Open Decoding}

Open decoding put the phenomenon of homogenization and correlation as well as the interview content into the same category and give its concept by organize raw data meticulously. And then refined similar concepts into the same category through continuous comparative analysis. Based on this, first takes agricultural transfer population citizenization as the core theme of social stability risk, then implements initial conceptualization and categorization. Through the open decoding, the collected raw data has been sort out, summed up the concept and further comparative analysis to extract the category.

\subsubsection{Spindle Decoding}

Open coding has many areas of social stability risk of agricultural transfer population, but these categories are relatively fragmented and isolated. Perform spindle decode according to the meaningful correlation and the potential intrinsic logic through One by one analysis the information on each category. Further we can get the main category.

\subsubsection{Core Decoding}

Based on the results of the spindle decode, analyze it systematically and form a core category of leadership. All the data are used to verify the internal relations of each category. Construct the roots theory model and then comprehensively explain the influencing factors of social stability risk in the citizenization of agricultural population. Taking "the social stability risk of agricultural transfer population" as the core theme, we can get the core category through analysis main category which was formed by spindle decoding. The comprehensive risk factors of agricultural transfer population are identified naturally [11].

\subsection{AHP-Fuzzy Comprehensive Evaluation Model Construction}

\subsubsection{Establish a Set of Factors}

According to the risk factor to determine the comprehensive evaluation factor level (set factors), establish a set of factors $U$ :

$$
U=\left\{U_{1}, U_{2}, U_{3} \ldots U_{n}\right\}
$$

\subsubsection{Determine the Comment Set}

In the evaluation of social stability risks within agricultural Transfer Population Citizenization, the risk degree is determined by the possibility of conflict and the attitude of the masses in the citizenization process. Among them, high risk indicates that most people have opinions on the citizenization of agricultural transfer population, and the reaction is particularly strong, which may lead to large-scale mass incidents. Medium risk indicates that some people have opinions on the citizenization of agricultural transfer population and have a strong reaction that may lead to conflict. Low risk indicates that most people have adapt to the citizenization, only a small number of people have views on the agricultural transfer population, which can prevented and resolved by reasonable measures[12]. The specific evaluation set is:

$$
V=\left(v_{1}, v_{2}, v_{3}\right)=(\text { High risk, Medium risk, Low risk) }
$$

\subsubsection{Determine the Fuzzy Comprehensive Judgment Matrix}

Recognize the risk level of each factor, and respectively find the attribution degree of the each level on the individual factors (known as fuzzy matrix or evaluation matrix) [13]:

$$
R_{i}=\left[\begin{array}{cccc}
r_{11} & r_{12} & \ldots & r_{1 m} \\
r_{21} & r_{22} & \ldots & r_{2 m} \\
\ldots & \ldots & \ldots & \ldots \\
r_{n 1} & r_{n 2} & \ldots & r_{n m}
\end{array}\right]_{n \times m}
$$

\subsubsection{Construct the Hierarchical Model and Judgment Matrix}

Based on the risk factors, the target layer, the criterion layer and the index layer in the hierarchical model of the evaluation are determined according to their (affiliation. And then identify the relative importance degree of the evaluation index within each level according to the hierarchical model and the 1-9 scale scale [14]. A series of the following judgment matrix is obtained in table1. 
Table1 A-BJudgment matrix

\begin{tabular}{c|c|c|c|c}
\hline $\mathrm{A}$ & $\mathrm{B}_{1}$ & $\mathrm{~B}_{2}$ & $\ldots$ & $\mathrm{B}_{\mathrm{n}}$ \\
\hline $\mathrm{B}_{1}$ & 1 & $\mathrm{a}_{12}$ & $\ldots$ & $\mathrm{a}_{1 \mathrm{n}}$ \\
\hline $\mathrm{B}_{2}$ & $\mathrm{a}_{21}$ & 1 & $\ldots$ & $\mathrm{a}_{2 \mathrm{n}}$ \\
\hline$\ldots$ & $\ldots$ & $\ldots$ & $\ldots$ & $\ldots$ \\
\hline $\mathrm{B}_{\mathrm{n}}$ & $\mathrm{a}_{\mathrm{n} 1}$ & $\mathrm{a}_{\mathrm{n} 2}$ & $\ldots$ & 1 \\
\hline
\end{tabular}

Where: $a_{i j}$ represents the relative layer $A$

$B_{i}$ Represents the index $B_{j}$ of the important proportion scale.

\subsubsection{Determine the Weights of Each Level and Establish the Weight Vector}

$$
w_{i}=\sum_{j=1}^{n} \frac{a_{i j}}{n}
$$

Where: $a_{i j}$-the element corresponding to the $\mathrm{i}$-th row in column $\mathrm{j}$ of the matrix $N$ - The number of elements

$$
\begin{gathered}
\bar{w}=\left[w_{1}, w_{2}, w_{3} \ldots, w_{i}\right]^{T}, i=1,2,3 \ldots, n \\
W_{i}=w_{i} / \sum_{i=1}^{n} w_{i}
\end{gathered}
$$

Normalize the $\bar{w}$ by the formula (3), then get a certain level of indicators relative to the previous layer of the weight vector $\bar{W}$.

$$
\bar{W}=\left[W_{1}, W_{2}, \ldots, W_{n}\right]^{T}
$$

From the formula (4), the maximum eigenvalue of the judgment matrix is calculated [15].

$$
\lambda_{\max }=\sum_{i=1}^{N} \frac{(A W)_{i}}{n W_{i}}, i=1,2, \ldots, n
$$

Where: $\lambda_{\max }$-the largest eigenvalue of the judgment matrix

$A$-judgment matrix

$N$-judgment matrix order

$W_{i}$-normalized weight of the -th index

$$
C I=\frac{\lambda_{\max }-n}{n-1}
$$

The $C I$ value is calculated by the formula (6), and the smaller the $C I$ value is the higher the degree of consistency within the judgment matrix. If $C I=0$, it shows that the judgment matrix is fully consistent [16]. However, when building the judgment matrix, the higher the order, the lower the degree of consistency. In order to eliminate the influence of the order within the judgment matrix on the consistency, the average randomness index $R I$ is introduced. The specific values are shown in Table 2.

Table 2 Average random consistency index value [12]

\begin{tabular}{c|c|c|c|c|c|c|c|c|c|c}
\hline Order & 1 & 2 & 3 & 4 & 5 & 6 & 7 & 8 & 9 & 10 \\
\hline RI value & 0.00 & 0.00 & 0.58 & 0.90 & 1.12 & 1.24 & 1.32 & 1.41 & 1.45 & 1.49 \\
\hline$C R=\frac{C I}{R I}$
\end{tabular}

Where: $C R$-random consistency ratio

$R I$ - mean random consistency index

The random consistency ratio $C R$ is calculated from formula (7). In general, the judgment matrix of order $n>2, C R<0.1$ means that the judgment matrix is satisfactory. On the other hand, which means it is necessary to adjust the judgment matrix to pass the consistency test [17].

After the above calculation, we get the weight set $A$. For example, the weight set 
$A=\left(a_{1}, a_{2}, \ldots, a_{n}\right)$ Of the target layer $U$.And similarly the weight sets of each criterion layers

Are obtained.

\subsubsection{AHP-Fuzzy Comprehensive Evaluation}

Calculate the fuzzy composition value. Using the fuzzy matrix synthesis operation and select the appropriate fuzzy operator then get a comprehensive evaluation index by using Matlab software for comprehensive fuzzy operation :

$$
B=A * R=\left(a_{1}, a_{2}, \ldots, a_{n}\right)\left[\begin{array}{cccc}
r_{11} & r_{12} & \ldots & r_{1 m} \\
r_{21} & r_{22} & \ldots & r_{2 m} \\
\ldots & \ldots & \ldots & \ldots \\
r_{n 1} & r_{n 2} & \ldots & r_{n m}
\end{array}\right]=\left(b_{1}, b_{2}, \ldots, b_{m}\right)
$$

The fuzzy comprehensive evaluation result vector is analyzed. The most common method used in practical applications is to get the final result based on the maximum membership principle.

\section{Analysis on the Evaluation of Social Stability Risk Within Agricultural Transfer Population in Heilongjiang Province}

\subsection{Risk Factor Identification Based on Roots Theory}

Select events from three processes of the agricultural transfer population citizenization in Heilongjiang Province. Such as Fuhua coal mine fire accident in Hegang City , Fujin mass incidents in Heilongjiang, farmers from Anqing were beaten for asking get back the wages in 2014, Daqing farmers' farmland were occupied, Jixi graphite pollution, farmers of Baikui town within Hulan engaged in drug trafficking incident, Zhaodong forced farmers "upstairs" demolition conflict and other 20 typical cases. Using the authoritative news reports of these cases and the site interview of participants and onlookers crowed as the raw material of the study. And add internet forum, blog as well as interview information as a supplement.

\subsubsection{Open Decoding}

Takes social stability risk of the agricultural transfer population citizenization in Heilongjiang province as the core theme and then implements initial conceptualization and categorization. Through the open decoding, the collected raw data has been sort out, summed up to 94 concepts.

Table 3 Conceptual process of case openness decoding

\begin{tabular}{|c|c|c|}
\hline Material and Date Information & Conceptualization & Categorization \\
\hline $\begin{array}{l}\text { a1 Fuhua coal mine of Hegang in Heilongjiang province } \\
\text { occurred a fire accident,31 miners were trapped underground. }\end{array}$ & a1Miners were trapped & $\begin{array}{l}\text { A1Coal mine’s } \\
\text { safety problem }\end{array}$ \\
\hline $\begin{array}{l}\text { a2 It is a small coal mine of the state-owned large mining are } \\
\text { which should be } \\
\text { closed in accordance with the provisions. }\end{array}$ & a2 The coal mine is illegal & $\begin{array}{l}\text { A2 The government } \\
\text { regulation is not in } \\
\text { place }\end{array}$ \\
\hline $\begin{array}{l}\text { a3 All the people who engaged in the specific management of } \\
\text { the production, safety, electromechanical, ventilated transport } \\
\text { miner and technical directors didn't have coal mine safety } \\
\text { certification, which are all belong to undocumented work. }\end{array}$ & a3 Undocumented work & $\begin{array}{l}\text { A3 Practitioners are } \\
\text { lack of expertise }\end{array}$ \\
\hline $\begin{array}{l}\text { a4 Long Coal Group and Shuang Mine initially take } \\
\text { responsibility and actively respond to the demands of the } \\
\text { masses. The majority of workers and citizens do not believe } \\
\text { rumors, do not spread negative information. }\end{array}$ & $\begin{array}{l}\text { a4 Positive response } \\
\text { a5 Rumors spread }\end{array}$ & $\begin{array}{l}\text { A4 Administrative } \\
\text { efficiency } \\
\text { A5 Rumors negative } \\
\text { effects }\end{array}$ \\
\hline $\begin{array}{l}\text { a6 Trains and roads of Qianjin town in Fujin were intercepted } \\
\text { by Changchunling farmers for farmers petition unsolved } \\
\text { within this area which caused farmers’ extremely angry on } \\
15: 11 \text { pm. April 15, } 2010 .\end{array}$ & $\begin{array}{l}\text { a6 The collective lying rail } \\
\text { Only for the petition } \\
\text { unsolved }\end{array}$ & A6Extreme petition \\
\hline
\end{tabular}


Note: It is subject to space constraints, this article only intercepts some of the table to illustrate the research process.

\subsubsection{Spindle Decoding}

There are 14 main categories in the spindle decoding, named the efficiency of government agencies, the behavior of government officials, the farmers' political participation, employment,

migrant workers ask for salaries ,the media communication, the integration of old and new citizens, land acquisition system, rights protection system, social security system, natural disasters, mainstream industry safety management, psychological perception, cultural change. The specific process is as follows in table4:

Table 4 Main Category of Spindle Decoding

\begin{tabular}{|c|c|c|}
\hline $\begin{array}{l}\text { The Main Category of the Social Stability Risk } \\
\text { Factors within Agricultural Transfer Population } \\
\text { Citizenization in Heilongjiang Province }\end{array}$ & Corresponding Category & $\begin{array}{l}\text { Relationship and } \\
\text { Connotation }\end{array}$ \\
\hline Efficiency of Government Agencies & $\begin{array}{l}\text { Government action is slow } \\
\text { Low administrative } \\
\text { efficiency } \\
\text { Government regulation is } \\
\text { not in place }\end{array}$ & $\begin{array}{l}\text { Comprehensively reflects } \\
\text { the grassroots government 's } \\
\text { administrative law } \\
\text { enforcement attitude }\end{array}$ \\
\hline Behavior of Government Officials & $\begin{array}{l}\text { Village cadres corruption } \\
\text { Government officials are } \\
\text { threatened by violence } \\
\text { Grassroots government } \\
\text { credibility is poor } \\
\text { Grassroots government } \\
\text { illegal land acquisition }\end{array}$ & $\begin{array}{l}\text { The government's } \\
\text { misconduct caused } \\
\text { dissatisfaction }\end{array}$ \\
\hline Farmers' Political Participation & $\begin{array}{l}\text { Conceal the truth } \\
\text { Land acquisition } \\
\text { information is opaque }\end{array}$ & $\begin{array}{l}\text { Concrete manifestation of } \\
\text { poor civil } \\
\text { politics participation }\end{array}$ \\
\hline Employment & $\begin{array}{l}\text { Job shortage } \\
\text { Poor professional } \\
\text { competitiveness }\end{array}$ & $\begin{array}{l}\text { The main reason for the } \\
\text { frequent unemployment of } \\
\text { the agricultural transfer } \\
\text { population } \\
\end{array}$ \\
\hline Migrant Workers Ask for Salaries, & $\begin{array}{l}\text { Delayed payment of wages } \\
\text { It is difficult to talk about } \\
\text { life } \\
\text { Extreme way of asking for } \\
\text { money } \\
\text { Lack of clear authority }\end{array}$ & $\begin{array}{l}\text { The main problem faced by } \\
\text { the rural population in the } \\
\text { city to make a living }\end{array}$ \\
\hline & & \\
\hline
\end{tabular}

Note: It is subject to space constraints, this article only intercepts some of the table to illustrate the research process.

The social stability risk of agricultural transfer population citizenization in Heilongjiang Province is determined gradually by the roots theory, including political risk, social risk, institutional risk, safety risk and perceived risk.

\subsection{Establishment of Social Stability Risk Model for Agriculture Transfer Population Citizenization in Heilongjiang Province}

According to the analysis of the social stability risk factors within the agricultural transfer population citizenization in Heilongjiang Province, the basic framework of the social stability risk evaluation index system is constructed, as shown in Figure2. 


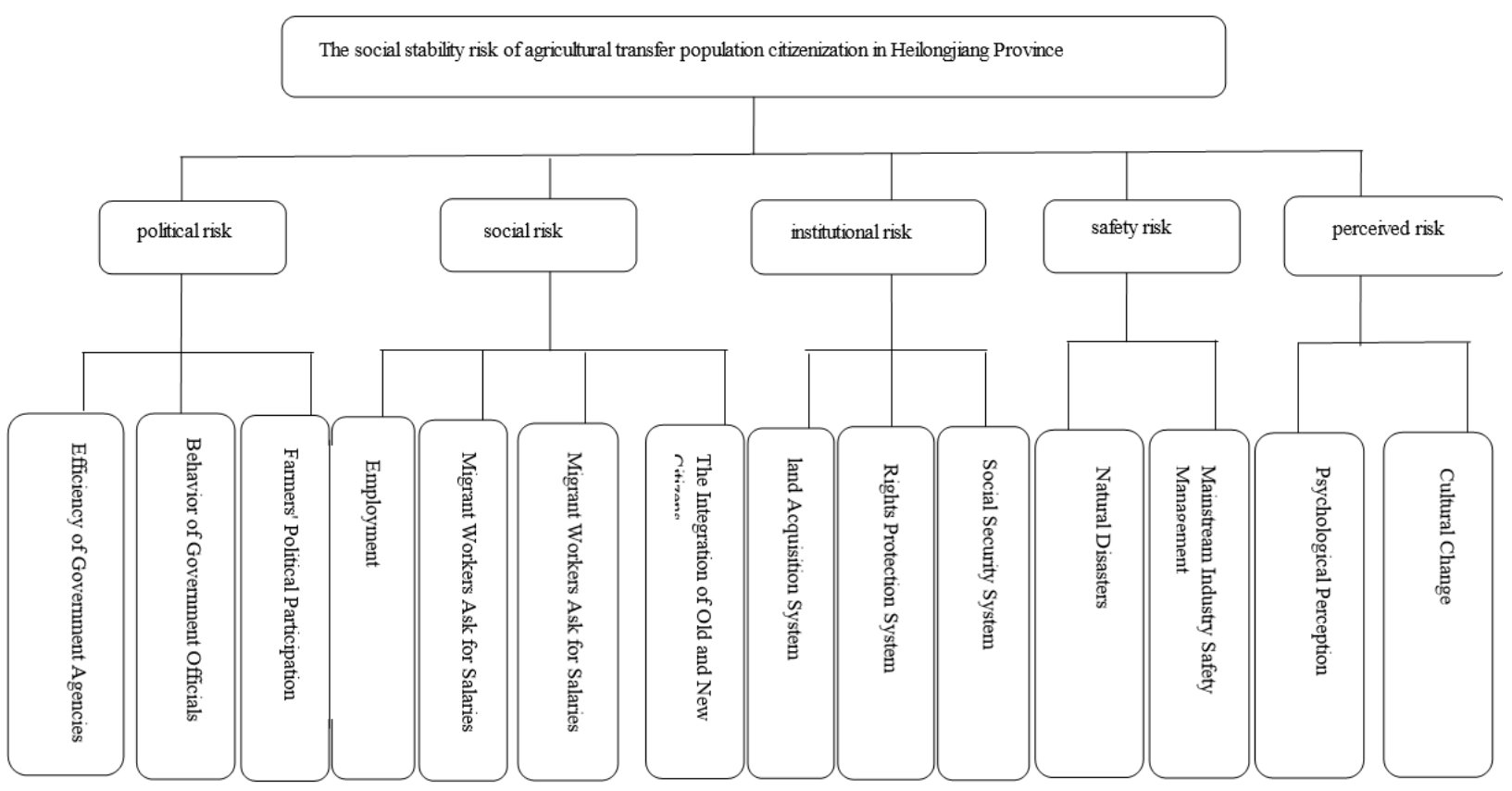

Figure 2 The social stability risk assessment index system of the agricultural transfer population citizenization in Heilongjiang

The evaluation factor set is consist of two levels, as follows:

(1)Level one evaluation indicators: $A=\left(B_{1}, B_{2}, B_{3}, B_{4}, B_{5}\right)$

$=($ Political risk, social risk, institutional risk, security risk, perceived risk)

(2) Level two evaluation index factor set

Political risk factors set: $B_{1}=\left(C_{11}, C_{12}, C_{13}\right)$

=(government agency efficiency, government officials, farmers' political participation)

Social risk factors set: $B_{2}=\left(C_{21}, C_{22}, C_{23}, C_{24}\right)$

= (employment, migrant workers pay, media, and new and old people fusion)

Institutional risk factors set: $B_{3}=\left(C_{31}, C_{32}, C_{33}\right)$

= (land acquisition system, rights system, social security system)

Safety risk factors set: $B_{4}=\left(C_{41}, C_{42}\right)$

$=$ (natural disasters, the mainstream industry safety management)

Perceived risk factors set: $B_{5}=\left(C_{51}, C_{52}\right)$

$=$ (psychological perception, cultural change)

The evaluation set is: $V=\left(v_{1}, v_{2}, v_{3}\right)=$ (high risk, moderate risk, low risk)

In this paper, 25 questionnaires were issued and 17 valid questionnaires were used. Sort out and count the individual risk factors membership through single factor evaluation of each evaluation index risk degree which are conducted by familiar experts in the field. Showing this data in table5. 
Table 5 The transfer of agricultural population stability of individual factors membership degree in Heilongjiang Province.

\begin{tabular}{|c|c|c|c|c|}
\hline Level one indicators & Level two indicators & High risk & Medium risk & Low risk \\
\hline \multirow{3}{*}{ Political riskB ${ }_{1}$} & Efficiency of government agenciesC $\mathrm{C}_{11}$ & $5(29.41 \%)$ & $10(58.82 \%)$ & $2(11.76 \%)$ \\
\hline & Behavior of government officials $\mathrm{C}_{12}$ & 6(35.29\%) & $10(58.82 \%)$ & $1(5.88 \%)$ \\
\hline & Farmers' political participation $\mathrm{C}_{13}$ & 6(35.29\%) & $9(52.94 \%)$ & $2(11.76 \%)$ \\
\hline \multirow{4}{*}{ Social riskB 2} & EmploymentC $\mathrm{C}_{21}$ & $8(47.06 \%)$ & $5(29.41 \%)$ & $4(23.53 \%)$ \\
\hline & Migrant workers ask for salaries $\mathrm{C}_{22}$ & $7(41.18 \%)$ & $7(41.18 \%)$ & $3(17.65 \%)$ \\
\hline & Media communication $\mathrm{C}_{23}$ & $4(23.53 \%)$ & $7(41.18 \%)$ & $6(35.29 \%)$ \\
\hline & The integration of old and new citizens $\mathrm{C}_{24}$ & 10(58.82\%) & $4(23.53 \%)$ & $3(17.65 \%)$ \\
\hline \multirow{3}{*}{ Institutional riskB 3} & Land acquisition systemC $C_{31}$ & $8(47.06 \%)$ & $6(35.29 \%)$ & $3(17.65 \%)$ \\
\hline & Rights protection $\mathrm{s}$ & $7(41.18 \%)$ & $7(41.18 \%)$ & $3(17.65 \%)$ \\
\hline & Social security system $\mathrm{C}_{33}$ & $9(52.94 \%)$ & $4(23.53 \%)$ & $4(23.53 \%)$ \\
\hline \multirow{2}{*}{ Safety risk $\mathrm{B}_{4}$} & Natural disasters $\mathrm{C}_{41}$ & 6(35.29\%) & $5(29.41 \%)$ & $6(35.29 \%)$ \\
\hline & Mainstream industry safety managementC $\mathrm{C}_{42}$ & $3(17.65 \%)$ & $8(47.06 \%)$ & $6(35.29 \%)$ \\
\hline \multirow{2}{*}{ Perceived riskB 5} & Psychological perceptionC $_{51}$ & $6(35.29 \%)$ & $6(35.29 \%)$ & $5(29.41 \%)$ \\
\hline & Cultural change $\mathrm{C}_{52}$ & $3(17.65 \%)$ & $6(35.29 \%)$ & $8(47.06 \%)$ \\
\hline
\end{tabular}

According to the statistical results above, the fuzzy evaluation matrix of each risk factor is:

$$
\begin{aligned}
& R_{1}=\left[\begin{array}{lll}
0.29 & 0.59 & 0.12 \\
0.35 & 0.59 & 0.06 \\
0.35 & 0.53 & 0.12
\end{array}\right], R_{2}=\left[\begin{array}{lll}
0.47 & 0.29 & 0.24 \\
0.41 & 0.41 & 0.18 \\
0.24 & 0.41 & 0.35 \\
0.59 & 0.23 & 0.18
\end{array}\right], R_{3}=\left[\begin{array}{lll}
0.47 & 0.35 & 0.18 \\
0.41 & 0.41 & 0.18 \\
0.52 & 0.24 & 0.24
\end{array}\right] \text {, } \\
& R_{4}=\left[\begin{array}{lll}
0.35 & 0.30 & 0.35 \\
0.18 & 0.47 & 0.35
\end{array}\right], R_{5}=\left[\begin{array}{lll}
0.35 & 0.35 & 0.30 \\
0.18 & 0.35 & 0.47
\end{array}\right]
\end{aligned}
$$

Through the expert consultation, we can separately get the judgment matrix of target layer and the criterion layer as well as the judgment matrix of criterion layer and index layer, as shown in Table 6 to Table 11:

Table 6 Judgment Matrix $A-B$

\begin{tabular}{c|c|c|c|c|c}
\hline $\mathrm{A}$ & $\mathrm{B}_{1}$ & $\mathrm{~B}_{2}$ & $\mathrm{~B}_{3}$ & $\mathrm{~B}_{4}$ & $\mathrm{~B}_{5}$ \\
\hline $\mathrm{B}_{1}$ & 1 & 3 & 1 & 6 & 4 \\
\hline $\mathrm{B}_{2}$ & $1 / 3$ & 1 & $1 / 3$ & 3 & $1 / 2$ \\
\hline $\mathrm{B}_{3}$ & 1 & 3 & 1 & 4 & 2 \\
\hline $\mathrm{B}_{4}$ & $1 / 6$ & $1 / 3$ & $1 / 4$ & 1 & $1 / 4$ \\
\hline $\mathrm{B}_{5}$ & $1 / 4$ & 2 & $1 / 2$ & 4 & 1 \\
\hline & & & & & \\
\hline
\end{tabular}

Table 7 Judgment Matrix $B_{1}-C$

\begin{tabular}{c|c|c|c}
\hline $\mathrm{B}_{1}$ & $\mathrm{C}_{11}$ & $\mathrm{C}_{12}$ & $\mathrm{C}_{13}$ \\
\hline $\mathrm{C}_{11}$ & 1 & $1 / 4$ & 3 \\
\hline $\mathrm{C}_{12}$ & 4 & 1 & 5 \\
\hline $\mathrm{C}_{13}$ & $1 / 3$ & $1 / 5$ & 1 \\
\hline
\end{tabular}

Table 8 Judgment Matrix $\quad B_{2}-C$

\begin{tabular}{c|c|c|c|c}
\hline $\mathrm{B}_{2}$ & $\mathrm{C}_{21}$ & $\mathrm{C}_{22}$ & $\mathrm{C}_{23}$ & $\mathrm{C}_{24}$ \\
\hline $\mathrm{C}_{21}$ & 1 & 3 & 7 & 2 \\
\hline $\mathrm{C}_{22}$ & $1 / 3$ & 1 & 3 & $1 / 3$ \\
\hline $\mathrm{C}_{23}$ & $1 / 7$ & $1 / 3$ & 1 & $1 / 5$ \\
\hline $\mathrm{C}_{24}$ & $1 / 2$ & 3 & 5 & 1 \\
\hline
\end{tabular}


Table 9 Judgment Matrix $B_{3}-C$

\begin{tabular}{c|c|c|c}
\hline $\mathrm{B}_{3}$ & $\mathrm{C}_{31}$ & $\mathrm{C}_{32}$ & $\mathrm{C}_{33}$ \\
\hline $\mathrm{C}_{31}$ & 1 & $1 / 3$ & $1 / 5$ \\
\hline $\mathrm{C}_{32}$ & 3 & 1 & $1 / 2$ \\
\hline $\mathrm{C}_{33}$ & 5 & 2 & 1 \\
\hline
\end{tabular}

Table 10 Judgment Matrix $B_{4}-C$

\begin{tabular}{c|c|c}
\hline $\mathrm{B}_{4}$ & $\mathrm{C}_{41}$ & $\mathrm{C}_{42}$ \\
\hline $\mathrm{C}_{41}$ & 1 & 3 \\
\hline $\mathrm{C}_{42}$ & $1 / 3$ & 1 \\
\hline
\end{tabular}

Table 11 Judgment Matrix $B_{5}-C$

\begin{tabular}{c|c|c}
\hline $\mathrm{B}_{5}$ & $\mathrm{C}_{51}$ & $\mathrm{C}_{52}$ \\
\hline $\mathrm{C}_{51}$ & 1 & 4 \\
\hline $\mathrm{C}_{52}$ & $1 / 4$ & 1 \\
\hline
\end{tabular}

From the above judgment matrix we can get that:

Level one evaluation index is:

$$
A=(0.3718,0.1135,0.2979,0.0530,0.1637)
$$

Level two evaluation index is:

$$
\begin{gathered}
A_{1}=\left(0.2311, \mathrm{~A} 3=(0.1096,0.3092,0.5813) ; A_{2}=(0.4797,0.1467,0.0592,0.3144) ;\right. \\
A_{3}=(0.1096,0.3092,0.5813) ; A_{4}=(0.7500,0.2500) ; A_{5}=(0.8000,0.2000)
\end{gathered}
$$

Making use of Matlab software to have comprehensive fuzzy operation on fuzzy evaluation matrix above $R_{i}$ and the weight index of each level two index $A_{i}$.Then get the $\mathrm{i}$ - th index of level one index contains the level two index which relatives to its comprehensive fuzzy operation $B_{i}$.Step by step, we get the fuzzy comprehensive evaluation matrix $R$ at last.

$$
\begin{gathered}
B_{1}=A_{1} * R_{1}=(0.2311,0.6651,0.1038) *\left[\begin{array}{lll}
0.29 & 0.59 & 0.12 \\
0.35 & 0.59 & 0.06 \\
0.36 & 0.53 & 0.12
\end{array}\right]=(0.3361,0.5838,0.0801) \\
B_{2}=A_{2} * R_{2}=(0.4797,0.1467,0.0592) *\left[\begin{array}{lll}
0.47 & 0.29 & 0.24 \\
0.41 & 0.41 & 0.18 \\
0.24 & 0.41 & 0.35 \\
0.59 & 0.23 & 0.18
\end{array}\right]=(0.4853,0.2958,0.2188) \\
B_{3}=A_{3} * R_{3}=(0.1096,0.3092,0.5813) *\left[\begin{array}{lll}
0.47 & 0.35 & 0.18 \\
0.41 & 0.41 & 0.18 \\
0.52 & 0.24 & 0.24
\end{array}\right]=(0.4806,0.3046,0.2149) \\
B_{4}=A_{4} * R_{4}=(0.7500,0.2500) *\left[\begin{array}{lll}
0.35 & 0.30 & 0.35 \\
0.18 & 0.47 & 0.35
\end{array}\right]=(0.3075,0.3425,0.3500) \\
B_{5}=A_{5} * R_{5}=(0.8000,0.2000) *\left[\begin{array}{lll}
0.35 & 0.35 & 0.30 \\
0.18 & 0.35 & 0.47
\end{array}\right]=(0.3160,0.3500,0.3340) \\
R=\left[\begin{array}{l}
B_{1} \\
B_{2} \\
B_{3} \\
B_{4} \\
B_{5}
\end{array}\right]=\left[\begin{array}{lll}
0.3361 & 0.5838 & 0.0801 \\
0.4853 & 0.2958 & 0.2188 \\
0.4806 & 0.3046 & 0.2149 \\
0.3075 & 0.3425 & 0.3500 \\
0.3160 & 0.3500 & 0.3340
\end{array}\right]
\end{gathered}
$$


Table 12 level one fuzzy comprehensive evaluation results

\begin{tabular}{c|c|c|c}
\hline \multirow{2}{*}{ Criteria layer indicators } & \multicolumn{3}{|c}{ Evaluation results } \\
\cline { 2 - 4 } & High risk & Medium risk & Low risk \\
\hline Political risk $\mathrm{B}_{1}$ & 0.3361 & 0.5838 & 0.0801 \\
\hline Social risk $\mathrm{B}_{2}$ & 0.4853 & 0.2958 & 0.2188 \\
\hline Institutional risk $\mathrm{B}_{3}$ & 0.4806 & 0.3046 & 0.2149 \\
\hline Safety risk $\mathrm{B}_{4}$ & 0.3075 & 0.3425 & 0.3500 \\
\hline Perceived risk $\mathrm{B}_{5}$ & 0.3160 & 0.3500 & 0.3340 \\
\hline
\end{tabular}

Based on the above results, conducting comprehensive fuzzy operation on the weight index of level one and level one fuzzy comprehensive evaluation results $R$. Then get the target layer contains each level one indicator which relatives to its comprehensive fuzzy operation $B$ of target layer $A$.

$$
\begin{aligned}
& B=A * R \\
& =(0.3718,0.1135,0.2979,0.0530,0.1637) *\left[\begin{array}{ccc}
0.3361 & 0.5838 & 0.0801 \\
0.4853 & 0.2958 & 0.2188 \\
0.4806 & 0.3046 & 0.2149 \\
0.3075 & 0.3425 & 0.3500 \\
0.3160 & 0.3500 & 0.3340
\end{array}\right]
\end{aligned}
$$$$
=(0.3912,0.4168,0.1919)
$$

Table 13 Level two fuzzy comprehensive evaluation results

Social stability risk of agricultural transfer population citizenization in

$$
\text { Heilongjiang Province }
$$

Evaluation results

\begin{tabular}{|c|c|c}
\hline $\begin{array}{c}\text { High } \\
\text { risk }\end{array}$ & $\begin{array}{c}\text { Medium } \\
\text { risk }\end{array}$ & $\begin{array}{c}\text { Low } \\
\text { risk }\end{array}$ \\
\hline 0.3912 & 0.4168 & 0.1919 \\
\hline
\end{tabular}

\subsection{Results Analysis}

(1) From the results of the level two fuzzy comprehensive evaluation, it can be seen that the probability of social stability risk within agricultural transfer population citizenization in Heilongjiang Province. The probability of high risk is $39 \%$, the probability of medium risk is $42 \%$ and the probability of low risk is $19 \%$.According to the principle of maximum membership, the level of social stability risk within agricultural transfer population citizenization in Heilongjiang Province is at the middle risk level. And the probability of $19 \%$ is at low risk. According to the principle of maximum membership, the social stability risk level of agricultural transfer population in Heilongjiang Province is in the middle risk level. In the process of citizenization, it is necessary to control the overall social stability of Heilongjiang Province through risk early warning and prevention measures. And reducing the risk level to low risk while preventing high risk development.

(2)Analyze the results of the level one fuzzy comprehensive evaluation according to the principle of maximum membership similarly. As can be seen from Table 12, social risk $B_{2}$ and institutional risk $B_{3}$ are high risk of social stability risk within agricultural transfer population citizenization in Heilongjiang Province. Political risk $B_{1}$ and perceived risk $B_{5}$ are the medium risk. Security risk $B_{4}$ is the low risk.

(3) From the overall situation of social stability risk within agricultural transfer population citizenization in Heilongjiang Province, the ranking of the level two indicators is as follows:

behavior of government officials $C_{12}>$ social security system $C_{33}>$ psychological perception $C_{51}>$ rights protection system $C_{32}>$ efficiency of government agencies $C_{11}>$ employment $C_{21}>$ natural disasters $C_{41}>$ farmers' political participation $C_{13}>$ the integration of old and new citizens $C_{24}>$ cultural change $C_{52}>$ land acquisition system $C_{31}>$ migrant workers ask for salaries $C_{22}>$ 
mainstream industry safety management $C_{42}>$ media communication $C_{23}$. Thus we can see that the citizanization of agricultural transfer population in Heilongjiang Province is dominated by the government. It is important to control the social stability risk for government action and institutional. Simultaneously, it has been proved that this new perspective, such as psychological and cultural changes, should be included in the maintenance mechanism.

\section{Conclusion}

Compared with the social stability risk evaluation index system of the major projects, the risk of media communication, psychological perception, integration and mainstream industry safety management has been increased in the level two indicators of this study, which reflects the grasp of the social stability risk factors in the specific environment of the agricultural transfer population in Heilongjiang Province. Stable risk factors. In the process of new citizenization, the agricultural transfer population is an important carrier of the three major industries as well as linkages between urban and rural, which have a wide influence on the overall development of citizenization and the overall social stability. Establish the evaluation model by the use of fuzzy AHP comprehensive evaluation method to evaluate the social stability risk within the agricultural transfer population can avoid the one-sidedness of the risk factors and the influence of subjective preference on objectivity in AHP. Applying this method in the evaluation of social stability risk within agricultural transfer population in Heilongjiang Province and compare it with previous evaluation results, further confirming its rationality, reliability and comprehensiveness.

About The Author

Xibo Sun (1979-), male, Qingdao Shandong Province, Associate Professor of School of Economics and Management Harbin Engineering University, Master tutor;

Xiaodong Shi (1992 - ), female, Heze Shandong Province, Master of School of Economics and Management Harbin Engineering University;

Peng Wang (1994 - ), female, Harbin, Heilongjiang, Master of School of Economics and Management Harbin Engineering University;

\section{Acknowledgments}

Heilongjiang Province Philosophy and Social Sciences Research Planning Project: "Research on Social Stabilization Risk and Governance of Citizens of Heilongjiang Province Agriculture Transplant Population” (15SHB04).

Social Science Fund Project (HEUCFW170910).

\section{References}

[1]. Jian Min, Nian Xingchang. Social Stability Risk of Farmers' Citizenization and Its' Governance[J].Theoretical Exploration.(2014)No. 3,p.74-77+90

[2]. Tong Xing. Social Stability Risk Assessment of Public Policy[J].Study and Practice.(2010)No. 9,p.114-119

[3]. Yang Fangyong. On the Application of Social Combustion Theory in "Significant Events"-Theoretical Basis and Method Model of Significant Events Social Stability Risk Assessment [J].Journal of Zhejiang Party School of C.P.C. (2012) No. 4, p.106-111

[4]. Guo Xiuyun. Significant Events: From "Social Impact Assessment" to "Social Stability Risk Assessment"[J].Advances in China Public Security.(2015)No.1,p.33-40

[5]. Cai Xiuyin. Reasonably Determined The Main Content of Social Stability Risk Assessment in Local Significant Events[J].Journal of Liaoning Academy of Governance.(2012)No.8 
[6]. Sun Qifeng. Research on Social Stability Risk Assessment Which Based on Economic Indicators [J].Research on Financial and Economic Issues. (2015)No3, p.16-23.

[7]. Chang D Y. Appliation of the extent analysis method of fuzzy AHP [J].European Journal of Operational Reasearch.Vol.95(1996),p.649-655

[8]. Hammersley M. The Dilemma of Qualitative Method: Herbert Blumer and the Chicago Tradition[M].London: Routledge,(1989)

[9]. Kathy Charmaz. Construct Roots Theory: Qualitative Research Practice Guide[M].Chongqing University Press.(2009),p.236+131

[10]. Glaser B.G. Advances in the Methodology of Grounded Theory: Theoretical Sensitivity [J]. Mill Valley CA: Social Press.(1978),p.91

[11]. Jia Zhemin. The Application of Roots Theory in Public Administration: Methods and practice [J].Chinese Public Administration. (2015)No. 3, p.90-95.

[12]. Fan Juan.Risk Assessment of Significant Project Based on AHP method [D].Southwestern University of Finance and Economics Master's Thesis.(2014),p.36-47

[13]. Fu Junming, Lu Dongsheng etc. Research on the Social Stability Risk Analysis of High way Based on Multi - level Fuzzy Theory[J].Transportation Science \& Technology.(2014)No. 1,p.143-146

[14]. T.L.Saaty, Saaty TL. Modeling unstructured decision problems-the theory of analytical hierarchies [J]. Math Comput Simulation, (1978) No20,p.147- 158

[15]. Ramanathan R.A note on the use of the analytic hierarchy process for environmental impact assessment. Journal of Environmental Management,Vol.63(2001),No.1,p.27-35

[16]. Cheng Shubo, Guo Manli. Social Stability Risk Assessment of Subway Construction Project Based on Analytic Hierarchy Process[J].Journal of Henan Polytechnic University(Social Sciences).(2014)No. 3,p.273-278

[17]. Wang Jun. Fuzzy Comprehensive Evaluation of Network Information Retrieval System[J].Journal of Intelligence.(2003)No. 8,p.53-54 